\title{
Development of Express Highways and Trauma Care Centers in Indian Scenario
}

\section{Akshat Pandey*}

Life Associate Member - Indian Society for Trauma and Acute Care (Jpn Apex Trauma Center AlIMS regd. 2064), India

\section{Introduction}

This is with reference to the recently constructed express national highways by the honorable state governments in India, for the sole purpose of speedy connectivity and hustle free transport from one place to another. The aim lies good as far as accidents do not occur. State governments are doing really excellent jobs by connecting major cities and metros across India but side by side creating an open space for accidents to happen and casualties to be added to annual tally of Indian Road traffic accidents list. We have express highways with very good road management. But we are lacking an excellent trauma management centers across express highways within approachable limit and well equipped ambulance system backup with across India toll free number as compared to any of the developed nation basically what constitutes express highways are speedy traffic in terms of two wheelers and four wheelers, absence of proper lightening polls, improper traffic sense and accident caused due to above mentioned factors to a certain extent accidents on national highways/express highways can be prevented as far as Indian scenario is concerned by managing following factors:

\section{Control driving}

It applies to all the vehicles running on highways irrespective of personal/private/or any other use.

\section{Standing of vehicles}

We have heard a lot about road traffic accidents where a moving vehicle had a head on collision with standing truck/without its light displayed causing right on spot. It is in our hand to display the emergency system of our vehicles if there is technical breakdown and it should be stand away from the road as far as possible as to avoid the impact of road side moving vehicles.

\section{Absence of proper lightening}

Its being observed on express highways that there are more toll plazas to collect the money as compared to electricity and light polls. This factor affects the safety protocols as laid down by International Road Safety Org. Compromising this creates lots of accidents in absence of proper lightening and electric polls and as far as casualties. Due to this factor can be averted by accurate safety measures.

\section{Proper traffic sense}

Proper traffic sense also constitutes an important factor in prevention of road traffic accidents. It includes judicial use of safety measures such as helmets for riders; safety belts in cars and other precautions as per the demand. It also include driving sense of vehicles i.e. be in one lane; use of lights when changing the lane; use of horn are some of the important factors which are crucial and critical for prevention of road traffic injuries and judicial use of above factors can lead to drastic change in reduction of deaths due to it.

\section{Specialized Trauma Centers and its Importance}

With reference to above mentioned sub heading following are two case scenarios which clearly prove the importance of specialized trauma centers across India.

\section{case 1}

In a first case near Mathura a road traffic accident occurred. It results into two casualties and one person critically injured battling for life at some private hospital in Mathura. In this post accident scenario rescue was done by local villagers with the help of some workers of JAYPEE Group. Rescue was compromised as per medical guidelines and in absence of expert medical assistance. Even the transport of injured was compromised in absence of equipped ambulance ethics of Golden Hour Management was compromised in absence of Trauma Center on Highway. Had there been good trauma center available then valuable time in transfer of patients would have been saved and possible two casualties would have been averted.

\section{case 2}

In a recent accident near Greater Noida on Delhi Agra express highway where a BMW car got damaged resulting into injuries to two boys and two girls on board. No casualties were reported since the area has bunch of medical setups/trauma management hospitals nearby. Rescue was done and medical aid was provided in time.

Comparative scenario - Both the case scenario represents the typical dissymmetrical approach of Indian society towards trauma management. In the first case we lack an established trauma set up and in second we have bunch of hospitals as the place is near to metropolitan. Absence of trauma centers in first case scenario causes death and bunch of hospitals in case 2 save lives of injured.

\section{Conclusion}

India requires more specialized trauma centers on express highways. They should either come under public private partnership or state government should initiate the trauma project of India parallel to express highways. They should also have guidelines at par to national trauma centers as that of AIIMS with proper connectivity to ambulances so that golden hour should be used judiciously irrespective of trauma obtained. Judiciously use of golden hour management itself saves lives. Ambulances and their contact number with all relative

*Corresponding author: Akshat Pandey, Life Associate Member - Indian Society for Trauma and Acute Care ( Jpn Apex Trauma Center AlIMS regd 2064) Life member -Indian Hernia Society AlIMS regd. no 687, D-1011 near Vishal X-ray clinic, Indiranagar, Lucknow 226016, Uttar Pradesh, India, E-mail: pandey.aiims@gmail.com

Received September 15, 2012; Accepted September 26, 2012; Published September 28, 2012

Citation: Pandey A (2012) Development of Express Highways and Trauma Care Centers in Indian Scenario. J Trauma Treat 1:147. doi:10.4172/2167-1222.1000147

Copyright: () 2012 Pandey A. This is an open-access article distributed under the terms of the Creative Commons Attribution License, which permits unrestricted use, distribution, and reproduction in any medium, provided the original author and source are credited. 
Citation: Pandey A (2012) Development of Express Highways and Trauma Care Centers in Indian Scenario. J Trauma Treat 1:147. doi:10.4172/21671222.1000147

Page 2 of 2

details should be displayed at all glow sign boards on express highways. There should be a quick response team specially dedicated for post trauma management on road.

Hope that concerned attached should think about trauma services and their importance side by side since it is rightly said by someone "accident or trauma can touch any one; at any given time and at any given place irrespective of his caste, creed and religion'. 